\title{
Article \\ Metabolic Syndrome and Psychological Effects of Exercise in Hemodialysis Patients
}

\author{
Beata Hornik $^{1, *(\mathbb{D} \text {, Jan Duława }}{ }^{2,3}\left(\mathbb{D}\right.$ and Jacek Durmała ${ }^{4}$ \\ 1 Department of Internal Nursing, School of Health Sciences in Katowice, Medical University of Silesia, \\ 40-752 Katowice, Poland \\ 2 Department of Internal Medicine and Metabolic Diseases, School of Health Sciences in Katowice, \\ Medical University of Silesia, 40-752 Katowice, Poland; jdulawa@sum.edu.pl \\ 3 Diaverum, 40-635 Katowice, Poland \\ 4 Department of Rehabilitation, School of Health Sciences in Katowice, Medical University of Silesia, \\ 40-752 Katowice, Poland; jdurmala@sum.edu.pl \\ * Correspondence: bhornik@sum.edu.pl; Tel.: +48-32-359-8277
}

Citation: Hornik, B.; Duława, J.; Durmała, J. Metabolic Syndrome and Psychological Effects of Exercise in Hemodialysis Patients. Int. J. Environ. Res. Public Health 2021, 18, 11952. https://doi.org/10.3390/ ijerph182211952

Academic Editor: José Carmelo Adsuar Sala

Received: 2 October 2021

Accepted: 10 November 2021

Published: 14 November 2021

Publisher's Note: MDPI stays neutral with regard to jurisdictional claims in published maps and institutional affiliations.

Copyright: (c) 2021 by the authors. Licensee MDPI, Basel, Switzerland. This article is an open access article distributed under the terms and conditions of the Creative Commons Attribution (CC BY) license (https:// creativecommons.org/licenses/by/ $4.0 /)$.

\begin{abstract}
Metabolic syndrome (MS) and anxiety disorders are common problems among hemodialysis patients (HD). However, there have been no studies defining the role of physical activity in reducing anxiety in HD patients with MS. This study was aimed to determine the effects on the severity of anxiety of a four-week rehabilitation program for HD patients, with or without metabolic syndrome (MS), planned and adapted to their abilities. The study was single-center, interventional, non-randomized, and prospective. Fifty-eight individuals completed the project (28 HD patients and 30 controls (C) with normal kidney function). Each group was divided into two subgroups with respect to MS. The mean age of the subjects in the HD and C groups was $56.9 \pm 13.3$ years $(\bar{x} \pm$ SD) and $61.5 \pm 8.3$ years $(\bar{x} \pm \mathrm{SD})$, respectively. Planned and adapted to the patient's abilities, the rehabilitation program based on physiotherapy was provided to each subject for 4 weeks. Baseline and post-intervention determined anxiety levels using the State-Trait Anxiety Inventory (STAI). The X1 scale tests state anxiety, and the $\mathrm{X} 2$ scale tests trait anxiety. Post-intervention, there was no significant difference in the intensity of state anxiety observed in HD patients compared to $C$ with normal renal function, as observed before the program. After four weeks of regular physical activity planned and adapted to the patient's abilities in an inpatient ward, the level of state anxiety (X1) and trait anxiety (X2) lowered considerably in all HD patients (respectively: $35.1 \pm 8.0$ vs. $29.2 \pm 5.0, p=0.001$ for $\mathrm{X} 1$ and $41.8 \pm 9.1$ vs. $38.1 \pm 5.9, p=0.008$ for $\mathrm{X} 2)$. The rehabilitation program significantly reduced the intensity of state anxiety (X1) in HD patients with MS (35.8 \pm 7.9 vs. $29.2 \pm 5.1 ; p=0.01)$. The rehabilitation program helped to significantly reduce the intensity of trait anxiety (X2) in HD patients without MS (41.9 \pm 10.7 vs. $36.9 \pm 5.9 ; p=0.04)$. Four-week physical activity planned and adapted to the patient's abilities reduces the intensity of anxiety in HD patients and controls with normal renal function. HD patients with MS benefit more in terms of reducing perceived state anxiety, and HD patients without MS in terms of reducing trait anxiety.
\end{abstract}

Keywords: metabolic syndrome; hemodialysis; physical activity; anxiety; rehabilitation

\section{Introduction}

Metabolic syndrome (MS) is a complex disorder characterized by a combination of factors. Each of those factors predisposes an individual to cardiovascular risk. The most frequently used diagnosis criteria are those proposed by the World Health Organization (WHO), the International Diabetes Federation (IDF), and the National Cholesterol Education Program-Adult Treatment Panel (NCEP ATP) [1].

According to various studies, MS occurs in about $50-75 \%$ of hemodialysis (HD) patients [2,3]. The estimates of the comorbidity of anxiety or depression and MS are also 
ambiguous [4-6]. Some authors indicate a relationship between MS and depression [7,8]. Others reveal only the relationship between MS and anxiety $[9,10]$.

Anxiety disorders are the most common mental health problem in the world. About eight percent of the population experience them once a year. Fourteen percent endure them at least once in their lives [11].

The prevalence of anxiety of varying severity in HD patients ranged from $12 \%$ to $52 \%$ in various studies [12-17]. An assessment of depression and suicide risk is always recommended whenever an anxiety disorder is diagnosed [18]. The source of anxiety in chronically HD patients is their current health status and the awareness of reduced control over their own lives. In the United States, withdrawal from dialysis treatment is the third leading cause of death in chronic kidney disease [19]. Moreover, studies show a causal relationship between anxiety and cardiovascular diseases [20-22]. Increased anxiety symptoms have also been demonstrated in patients after cardiac incidents. They are related to a twofold increase in the risk of death in patients after coronary artery bypass graft and outpatient patients with coronary artery disease [20,23-25].

Physical activity is a recognized non-pharmacological method of reducing anxietydepressive symptoms [26-28]. The beneficial effect of increased physical activity on reducing anxiety in healthy people has been well documented [29-32]. Conversely, lack of physical activity has been identified as a risk factor for the development of anxiety [33]. However, few studies determine the impact of physical activity on experiencing anxiety in HD patients [34-36]. Most of the studies in these patients focused on the beneficial effect of physical activity on reducing depression symptoms [37-39]. It seems, therefore, essential to develop the most effective training models to improve the mental and functional condition of dialysis patients [40].

An additional argument for researching the impact of physical activity on anxiety disorders, including the role of metabolic syndrome, is the phenomenon of reversed epidemiology observed in uremic patients [41,42]. Numerous reports on reverse epidemiology deal with the components of MS. The findings that hyperlipidemia and above-normal body weight may be protective could indicate that general rules of epidemiology may not apply to uremic patients $[43,44]$. However, $\mathrm{Lu}$ et al. point out that these factors are no longer protective in patients over 65 [45].

Although there is evidence of the effect of physical activity on treating anxiety [46-48], it has not thus far been the subject of research in the context of MS in HD patients. Such an undertaking could provide new information.

Considering the presented facts, it seemed warranted to determine the effect of physical activity on experiencing anxiety depending on the presence or absence of MS. It has been hypothesized that an organized rehabilitation program inhibits fear and anxiety and that the effect may vary depending on the presence of MS. This study was aimed to determine the effects on the severity of anxiety of a four-week rehabilitation program for HD patients with or without metabolic syndrome (MS), planned and adapted to their abilities.

\section{Participants and Methods}

A detailed description of patient enrolment and the study methodology was included in our previous paper [49]. Therefore, we present here an abridged description of the study group and measurements.

\subsection{Study Design}

The study was conducted between January 2013 and December 2016. This was a single-center, interventional, non-randomized prospective study. The study was part of a broader study, part of which was presented in a different context [49], but it was primary research during which new data was collected. 


\subsection{Eligibility Criteria}

\subsubsection{Inclusion Criteria}

The criteria for patient inclusion in the study were: age $>18$ years, stage 5 chronic kidney disease and hemodialysis treatment duration $>3$ months (for the study group) or normal kidney function (assessed by e GFR, general urinalysis, $24 \mathrm{~h}$ albumin excretion, and renal ultrasound results) - for the control group, the ability of the subject to perform low-level intensity exercise and written informed consent for participation in the study.

\subsubsection{Exclusion Criteria}

The criteria for exclusion from the study were: a systemic rheumatic disease, cancer, conditions preventing/inability to perform low-level intensity exercise (New York Heart Association class IV heart failure, advanced mobility disorders), overt infection within the last three months, immunosuppressive treatment, pregnancy, and refusal to participate in the study.

\subsection{Participants and Recruitment}

All study participants received printed information about the purpose and manner of the study, and those who decided to participate in the study gave their written consent. These subjects were recruited at the dialysis center in Katowice, Poland. The control group consisted of patients with a normal renal function who participated in a four-week outpatient cardiac rehabilitation program. These subjects were recruited at the Department of Rehabilitation at University Hospital (No. 7 SUM, Upper Silesian Medical Center, Katowice, Poland). Those dialysis center patients who met the inclusion criteria were welcome to participate in the study. In total, 80 subjects were invited to participate in the research (40 dialysis patients and 40 with normal kidney function). Ultimately, sixty-two subjects agreed to participate in the study: 31 dialysis patients and 31 subjects with normal kidney function participating in the rehabilitation program. Fifty-eight completed the project (28 dialysis patients and 30 subjects with normal kidney function).

The reasons HD patients discontinued physical activity included repeated stenocardia pain (one patient who was referred to the cardiology department), worsening of depression (one patient), and loss of motivation (one patient). In the control group, one patient was withdrawn because of loss of motivation.

\subsubsection{Assessment of Metabolic Syndrome}

The study group and the control group were divided into two subgroups. The distribution criterion was the presence or absence of metabolic syndrome (MS). The MS criterion was adopted according to the 2009 common position of the International Diabetes Federation (IDF) in agreement with the National Heart Institute, Lungs and Blood (NHLBI) and the American Heart Association (AHA) [50]. Diagnosis of MS was based on the presence of at least three out of five distinct, clinically relevant cardio-metabolic risk factors for the European population. The components assessed when diagnosing metabolic syndrome are waist circumference, high-density lipoprotein (HDL), fasting serum triglyceride and glucose concentration, and blood pressure. Its prevalence varies depending on the accepted definition and ethnicity.

The patients were divided into the following groups: study group-hemodialysis patients (HD): patients with metabolic syndrome (14 patients) (HD-MS subgroup); patients without metabolic syndrome (14 patients) (HD-nMS subgroup); control group-subjects with normal renal function undergoing cardiac rehabilitation (C): subjects with metabolic syndrome (13 subjects) (C-MS subgroup), subjects without metabolic syndrome (17 subjects) (C-nMS subgroup). These subjects were recruited at the dialysis center in Katowice, Poland. A control group (C) comprised 30 consecutive patients of the rehabilitation day ward These subjects were recruited at the Department of Rehabilitation at University Hospital. Written informed consent was obtained from each subject after the aim of the study, protocol, and risks were presented and explained. 
The mean age of the subjects in the HD and C groups was $56.9 \pm 13.3$ years $(\bar{x} \pm \mathrm{SD}$; in the range from 25 to 75 years) and $61.5 \pm 8.3$ years ( $\bar{x} \pm \mathrm{SD}$; in the range from 37 to 76 years), respectively. The HD patient group consisted of 16 women (57\%) and 12 men $(43 \%)$. The group of patients with normal renal function consisted of 15 women $(50 \%)$ and 15 men $(50 \%)$.

\subsubsection{Assessment of Anxiety}

We determined each subject's anxiety level before and after the rehabilitation using the State-Trait Anxiety Inventory (STAI) [51]. The Polish version of STAI published in 2011 by the copyright owner (Psychological Test Laboratory of the Polish Psychological Association, Warsaw 2011, Poland) was used [52]. The structure of STAI measures the distinction between anxiety understood as transient and the situational condition of the individual and anxiety understood as a relatively constant personality trait. The X1 scale tests state anxiety, and the X2 scale tests trait anxiety. Each of them consists of 20 statements.

The statements included in the scale are formulated in such a way that the highest fear is indicated alternately by the number 4 (a direct statement) or the number 1 (an indirect statement). That prevents mechanical responses and minimizes the impact of nodding. All test items that require result transformation are available in the key. After the switch, the numerical values of responses were added up. A raw score was calculated for a given scale ranging from twenty to eighty. A higher value of the result indicates a greater level of fear and anxiety.

All test items that require result transformation are available in the key. After the switch, the numerical values of responses were added up. A raw score was calculated for a given scale ranging from twenty to eighty. A higher value of the result indicates a greater level of fear and anxiety. The STAI-S and STAI-T scales were conducted using the paper and pencil method. They required direct contact between a dialysis nurse and the patient. The results were assessed by a psychologist who did not know who was from the control group and who was from the study group.

\subsection{Ethics Statement}

The study was conducted following the Helsinki Declaration after the Bioethical Committee of the Medical University of Silesia in Katowice approved the project (Resolution No. KNW/0022/KB1/44/II/06/14/17).

\subsection{Exercise Program}

Before qualifying for the exercise program, all participants had a detailed medical history (the course of the disease, the duration of dialysis treatment), a physical examination, and anthropometric measurements were taken. Before planning an exercise program, a multidisciplinary team assessed locomotion, self-service ability, manual dexterity, balance, range of motion in the spine and peripheral joints, physical performance, and cardiovascular risk. Due to the various possibilities, exercises were customized to match individual capabilities. An individualized supervised rehabilitation program based on physiotherapy was provided to each subject for 4 weeks, 6 days a week, $2 \mathrm{~h}$ a day. This program included 20-40 $\mathrm{min}$ ( $25 \pm 10 \mathrm{~min}$ ) of aerobic endurance training (AET) — walking, treadmill walking, forward and back walking, and cycling on stationary ergometers. Every time, the intensity of exercise was closed to ventilatory anaerobic threshold (VAT). During all sessions of AET, the rating of perceived exertion based on Borg 6-20 scale was below 13. It is a subjective method of assessing physical capacity [53]. All patients completed at least $90 \%$ of the planned training sessions.

This exercise was complemented with balance and coordination exercises, isometric exercises, exercises in part or full unloading, free active exercises, relaxing exercises, and active breathing exercises. The massage technique and various methods of physical therapy were also used. Most individuals received classic local massage and electrotherapy methods-TENS (transcutaneous electrical nerve stimulation) currents. Of the several 
electromagnetic treatment methods, mainly constant and low-frequency magnetic fields have been used. In addition to kinesiotherapy, massage, and electrotherapy, light therapy was used, including point laser therapy and local ultrasound.

\subsection{Statistical Methods}

Statistical analyses were performed using the Statistica 13.1 program (StatSoft, Inc., Tulsa, OK, USA). The results of quantitative variables are presented as the mean and standard deviation $(\bar{x} \pm \mathrm{SD})$ or on the basis of the median. Qualitative variables measured on nominal and ordinal scales (e.g., education) are presented as numbers $(n)$ and percentages $(\%)$.

The normality of the empirical distribution of quantitative variables was assessed by the Shapiro-Wilk test. The Mann-Whitney U test was used for non-parametric variables. The Student's paired t-test for pairs of observations (provided that the distribution was normal) was used to compare the differences or the Wilcoxon test with a distribution deviating from the normal. The result was considered significant if $p<0.05$.

\section{Results}

The most common causes of chronic kidney disease were: glomerulonephritis (25.1\%), diabetic kidney disease (21.4\%), and hypertensive nephropathy (21.4\%). The mean comorbidity index (Comorbidity Index CI) in the HD and C groups was: $4.5 \pm 3.6$ and $1.03 \pm 0.61$, respectively $(p<0.001)$.

HD patients were treated with repeated hemodialysis for $50.6 \pm 73.4$ months (5 to 272 months). Vascular access was provided by arterio-venous (AV) fistula formation in 24 patients $(85.7 \%)$, in the remaining patients-by implantation of a synthetic AV graft or using a dialysis catheter. Classic bicarbonate dialysis treatments lasted from 4 to $4.5 \mathrm{~h}$ and took place three to 5 times a week using high-flux dialyzers. The dialysis fluid flow was $500 \mathrm{~mL} / \mathrm{min}$, and the blood flow was $250-350 \mathrm{~mL} / \mathrm{min}$. The dialysis adequacy index $(\mathrm{Kt} / \mathrm{V})$ was $1.41 \pm 0.23$. Groups HD and C were similar demographically and anthropometrically. The study group and the control group were comparable with respect to age, sex, body weight, and BMI (Table 1).

Table 1. Baseline characteristics of patients participating in the study $(n=58)$.

\begin{tabular}{|c|c|c|c|}
\hline Variables & Study Group (HD) & Control Group (C) & $p$-Value \\
\hline Age (years) & $\begin{array}{c}56.9 \pm 13.3 \\
(\text { range }=25-75)\end{array}$ & $\begin{array}{c}61.5 \pm 8.3 \\
(\text { range }=37-76)\end{array}$ & 0.12 \\
\hline Sex, $n(\%)$ female $/$ male & $16(57) / 12(43)$ & $15(50) / 15(50)$ & 0.61 \\
\hline Dialysis vintage (months) & $50.6 \pm 73.4($ range $=5-272)$ & - & \\
\hline $\begin{array}{c}\text { Frequency of dialysis, } n(\%) \\
3 \text { times per week } \\
4 \text { times per week } \\
5 \text { times per week }\end{array}$ & $\begin{array}{c}24(85.7) \\
3(10.7) \\
1(3.6)\end{array}$ & - & \\
\hline Dialysis adequacy $(K t / V)$ & $1.41 \pm 0.23$ & - & \\
\hline $\mathrm{BMI}\left(\mathrm{kg} / \mathrm{m}^{2}\right)$ & $\begin{array}{c}27.1 \pm 6.08 \\
(\text { range }=16.4-42.1)\end{array}$ & $\begin{array}{c}29.2 \pm 5.3 \\
(\text { range }=21.3-41.0)\end{array}$ & 0.16 \\
\hline Weight (kg) & $\begin{array}{c}74.1 \pm 20.1 \\
(\text { range }=43-126)\end{array}$ & $\begin{array}{c}79.9 \pm 17.7 \\
(\text { range }=53-117)\end{array}$ & 0.25 \\
\hline $\begin{array}{l}\text { Vascular access, } \mathrm{n}(\%) \\
\text { arteriovenous fistulas } \\
\text { arteriovenous grafts } \\
\text { central venous catheters }\end{array}$ & $\begin{array}{l}24(85.6) \\
2(7.2) \\
2(7.2)\end{array}$ & - & \\
\hline
\end{tabular}


Table 1. Cont.

\begin{tabular}{|c|c|c|c|}
\hline Variables & Study Group (HD) & Control Group (C) & $p$-Value \\
\hline $\begin{array}{c}\text { Cause of end-stage kidney disease, } n(\%) \\
\text { glomerulonephritis } \\
\text { diabetic kidney disease } \\
\text { hypertension nephropathy } \\
\text { other }\end{array}$ & $\begin{array}{l}7(25.1) \\
6(21.4) \\
6(21.4) \\
9(32.1)\end{array}$ & - & \\
\hline CCI (point) & $\begin{array}{c}4.5 \pm 3.6 \\
(\text { range }=2-13)\end{array}$ & $\begin{array}{c}1.03 \pm 0.61 \\
\text { (range }=0-2 \text { ) }\end{array}$ & 0.001 \\
\hline Metabolic syndrome, $n(\%)$ & $14(50)$ & $13(43.3)$ & 0.79 \\
\hline Diabetes, $n(\%)$ & $7(25)$ & $4(14.3)$ & 0.32 \\
\hline Waist circumference $(\mathrm{cm})$ & $\begin{array}{c}96.3 \pm 17.0 \\
(\text { range }=72-126)\end{array}$ & $\begin{array}{c}96.7 \pm 13.4 \\
(\text { range }=77-129)\end{array}$ & 0.92 \\
\hline Estimated GFR $\left(\mathrm{mL} / \mathrm{min} / 1.73 \mathrm{~m}^{2}\right)$ & $9.3 \pm 3.6$ & $97.6 \pm 28.1$ & $<0.001$ \\
\hline Hemoglobin $(\mathrm{g} / \mathrm{dL})$ & $11.16 \pm 1.34$ & $13.85 \pm 0.81$ & $<0.001$ \\
\hline Uric acid (mg/dL) & $5.24 \pm 1.44$ & $5.96 \pm 1.58$ & 0.08 \\
\hline Creatinine (mg/dL) & $6.750 \pm 2.435$ & $0.843 \pm 0.156$ & $<0.001$ \\
\hline Phosphorus (mg/dL) & $5.234 \pm 1.264$ & $1.277 \pm 0.209$ & $<0.001$ \\
\hline Sodium (mmol/dL) & $139.6 \pm 2.9$ & $139.4 \pm 2.0$ & 0.70 \\
\hline Potassium (mmol/dL) & $5.230 \pm 0.522$ & $4.743 \pm 0.431$ & $<0.001$ \\
\hline PTH (pg/mL) & $210.1 \pm 187.8$ & $55.41 \pm 25.39$ & $<0.001$ \\
\hline $\mathrm{X} 1$ & $35.1 \pm 8.0$ & $30.3 \pm 7.0$ & 0.01 \\
\hline $\mathrm{X} 2$ & $41.8 \pm 9.1$ & $39.9 \pm 9.4$ & 0.53 \\
\hline
\end{tabular}

Note: Results are the mean \pm standard deviation (SD) or numbers (and percentages); significant at $p$-value $<0.05$. Abbreviations: BMI, body mass index; CCI, Charlson Comorbidity Index; GFR, glomerular filtration rate; PTH, parathyroid hormone; X1, state anxiety; X2, trait anxiety.

3.1. Comparison of the Level of Anxiety in Patients on Dialysis (HD) and Controls with Normal Kidney Function (C)

The level of state anxiety in HD patients (X1) was significantly higher than in individuals in group C (35.1 \pm 8.0 vs. $30.3 \pm 7.0 ; p=0.01)$. Trait anxiety $(\mathrm{X} 2)$ level was higher in HD patients, but the difference was non-significant ( $41.8 \pm 9.1$ vs. $39.9 \pm 9.4 ; p=0.53)$ (Table 1).

\subsection{Comparison of the Level of Anxiety in HD Patients with MS (HD-MS) and without MS} (HD-nMS)

Differences between state anxiety and trait anxiety levels between HD patients with metabolic syndrome and without MS patients were statistically non-significant (respectively: $35.8 \pm 7.9$ vs. $34.5 \pm 8.2, p=0.43$ for $\mathrm{X} 1$ and $41.7 \pm 7.5$ vs. $41.9 \pm 10.7, p=0.96$ for X2) (Table 2).

3.3. Comparison of the Level of Anxiety in Controls with Normal Kidney Functions with Metabolic Syndrome (C-MS) and Controls with Normal Kidney Function without Metabolic Syndrome (C-nMS)

Differences in experiencing anxiety in terms of state anxiety severity between C-MS and C-nMS individuals with normal kidney function were statistically non-significant (respectively: $29.1 \pm 6.6$ vs. $31.2 \pm 7.3, p=0.37$ for $\mathrm{X} 1$ and $39.7 \pm 9.4$ vs. $40.1 \pm 9.7, p=0.83$ for X2) (Table 2). 
3.4. Comparison of the Level of Anxiety in HD Patients and Individuals of the Control Group (C), Taking into Account the Presence or Absence of Metabolic Syndrome

The state anxiety level (X1) in HD-MS patients was considerably higher than in C-MS patients (35.8 \pm 7.9 vs. $29.1 \pm 6.6 ; p=0.03)$. The difference was not apparent in patients without metabolic syndrome: the intensity of state anxiety in HD-nMS patients did not differ significantly from the control group (C-nMS) ( $34.5 \pm 8.2$ vs. $31.2 \pm 7.3 ; p=0.26)$.

In HD-MS patients, the intensity of trait anxiety (X2) was higher than in patients with normal renal function (C-MS) ( $41.7 \pm 7.5$ vs. $39.7 \pm 9.4 ; p=0.66)$, but it was not a statistically significant difference. The difference in trait anxiety intensity (X2) between the HD-nMS and C-nMS subgroups $(41.9 \pm 10.7$ vs. $40.1 \pm 9.7 ; p=0.83)$ was also non-significant (Table 2).

Table 2. Baseline comparison of the level of anxiety in the study (HD) and control group (C) with metabolic syndrome (MS) and without metabolic syndrome (nMS).

\begin{tabular}{|c|c|c|c|c|c|c|}
\hline & \multicolumn{2}{|c|}{$\begin{array}{l}\text { Study Group } \\
\text { (HD) }\end{array}$} & \multicolumn{2}{|c|}{$\begin{array}{l}\text { Control Group } \\
\text { (C) }\end{array}$} & \multicolumn{2}{|c|}{$\begin{array}{l}p \text {-Value } \\
\text { HD vs. C }\end{array}$} \\
\hline & $\begin{array}{c}\text { HD-MS } \\
n=14\end{array}$ & $\begin{array}{c}\text { HD-nMS } \\
n=14\end{array}$ & $\begin{array}{l}\text { C-MS } \\
n=13\end{array}$ & $\begin{array}{c}\text { C-nMS } \\
n=17\end{array}$ & $\begin{array}{l}\text { HD-MS } \\
\text { vs. C-MS }\end{array}$ & $\begin{array}{l}\text { HD-nMS } \\
\text { vs. C-nMS }\end{array}$ \\
\hline $\mathrm{X} 1(\bar{x} \pm \mathrm{SD})$ & \multicolumn{2}{|c|}{$p=0.43$} & $29.1 \pm 6.6$ & $p=0.37$ & 0.03 & 0.26 \\
\hline $\mathrm{X} 2(\bar{x} \pm \mathrm{SD})$ & $p=0.96$ & $41.9 \pm 10.7$ & $39.7 \pm 9,4$ & $40.1 \pm 9.7$ & 0.66 & 0.84 \\
\hline
\end{tabular}

Note: Results are the mean $\pm \mathrm{SD}$; significant at $p$-value $<0.05$. Abbreviations: $\mathrm{X} 1$, state anxiety; $\mathrm{X} 2$, trait anxiety; HD, hemodialysis patients; C, patients with normal renal function; HD-MS, hemodialysis patients with metabolic syndrome; HD-nMS, hemodialysis patients without metabolic syndrome; C-MS, patients with normal renal function with metabolic syndrome; C-nMS, patients with normal renal function without metabolic syndrome.

\subsection{The Influence of Physical Activity Planned and Adapted to the Patient's Abilities on Tested Parameters}

After four weeks of regular exercise in an inpatient ward, the level of state anxiety (X1) and trait anxiety (X2) lowered considerably in all HD patients (respectively: $35.1 \pm 8.0 \mathrm{vs}$. $29.2 \pm 5.0, p=0.001$ for $\mathrm{X} 1$ and $41.8 \pm 9.1$ vs. $38.1 \pm 5.9, p=0.008$ for $\mathrm{X} 2$ ). A similar change was also observed in all subjects with normal renal function (respectively: $30.3 \pm 7.0$ vs. $27.8 \pm 6.7, p=0.05$ for $\mathrm{X} 1$ and $39.9 \pm 9.4$ vs. $36.8 \pm 7.2, p=0.003$ for $\mathrm{X} 2$ ).

After the rehabilitation program, there was no significant difference in the intensity of state anxiety observed in HD patients compared to patients with normal renal function, as observed before the program (29.2 \pm 5.0 vs. $27.8 \pm 6.7 ; p=0.21)$ (Table 3$)$. More data are provided in Supplementary Tables S1 and S3.

Table 3. Effect of rehabilitation program on the studied parameters in study (HD) and control group (C).

\begin{tabular}{cccccc}
\hline & \multicolumn{2}{c}{$\begin{array}{c}\text { Study Group } \\
\text { (HD) }\end{array}$} & \multicolumn{2}{c}{$\begin{array}{c}\text { Control Group } \\
\text { (C) }\end{array}$} & \multicolumn{2}{c}{$p$-ValueHD } \\
vs. C
\end{tabular}

Note: Results are the mean $\pm \mathrm{SD}$; significant at $p$-value $<0.05$. Abbreviations: $\mathrm{X} 1$, state anxiety; $\mathrm{X} 2$, trait anxiety; HD, hemodialysis patients; C, patients with normal renal function. 


\subsection{The Influence of Physical Activity Planned and Adapted to the Patient's Abilities on Tested Parameters in Patients with Metabolic Syndrome}

The rehabilitation program significantly reduced the intensity of anxiety state (X1) in HD-MS patients ( $35.8 \pm 7.9$ vs. $29.2 \pm 5.1 ; p=0.01)$. A similar change occurred in the C-MS group (29.1 \pm 6.6 vs. $24.8 \pm 3.5 ; p=0.02)$. After the rehabilitation program, the difference in the severity of state anxiety (X1) between HD-MS and C-MS was still significant (29.2 \pm 5.1 vs. $24.8 \pm 3.5 ; p=0.04$ ).

After the rehabilitation program, a statistically significant reduction in trait anxiety level (X2) was observed in subjects with normal C-MS renal function $(39.7 \pm 9.4 \mathrm{vs}$. $35.6 \pm 6.5 ; p=0.04)$. In the HD-MS subgroup, the intensity of trait anxiety (X2) also decreased. However, this change was minimal (41.7 \pm 7.5 vs. $39.3 \pm 5.8 ; p=0.10)$. After the rehabilitation program, as before the program, the difference in the intensity of trait anxiety (X2) between HD-MS and C-MS was non-significant (Table 4). More data are provided in Supplementary Tables S2 and S4.

Table 4. Effect of rehabilitation program on the studied parameters in the study (HD) and control group (C) with metabolic syndrome (MS).

\begin{tabular}{|c|c|c|c|c|c|c|}
\hline & \multicolumn{2}{|c|}{$\begin{array}{l}\text { Study Group } \\
\text { (HD-MS) }\end{array}$} & \multicolumn{2}{|c|}{$\begin{array}{l}\text { Control Group } \\
\text { (C-MS) }\end{array}$} & \multicolumn{2}{|c|}{$\begin{array}{c}p \text {-Value } \\
\text { HD-MS vs. C-MS }\end{array}$} \\
\hline & Before & After & Before & After & Before & After \\
\hline $\mathrm{X} 1(\bar{x} \pm \mathrm{SD})$ & \multicolumn{2}{|c|}{$p=0.01$} & $29.1 \pm 6.6$ & $24.8 \pm 3.5$ & 0.03 & 0.04 \\
\hline $\mathrm{X} 2(\bar{x} \pm \mathrm{SD})$ & $41.7 \pm 7.5$ & $39.3 \pm 5.8$ & $39.7 \pm 9.4$ & $35.6 \pm 6.5$ & 0.66 & 0.21 \\
\hline
\end{tabular}

Note: Results are the mean \pm SD; significant at $p$-value $<0.05$. Abbreviations: X1, state anxiety; X2, trait anxiety; HD-MS, hemodialysis patients with metabolic syndrome; C-MS, patients with normal renal function with metabolic syndrome.

3.7. The Influence of Physical Activity Planned and Adapted to the Patient's Abilities on the Tested Parameters in Patients without Metabolic Syndrome

In subjects without the metabolic syndrome: HD-nMS and C-nMS, the rehabilitation program resulted in a statistically insignificant reduction in the intensity of anxiety state (X1) (respectively: $34.5 \pm 8.2$ vs. $29.1 \pm 5.1, p=0.09$ for HD-nMS and $31.2 \pm 7.3$ vs. $30.1 \pm 7.7, p=0.54$ for C-nMS). After the rehabilitation program, the intensity of state anxiety (X1) in HD-nMS patients was lower than u C-nMS, but the difference was not significant $(29.1 \pm 5.1$ vs. $30.1 \pm 7.7 ; p=0.95)$.

The rehabilitation program helped to significantly reduce the intensity of trait anxiety $(X 2)$ in HD-nMS patients $(41.9 \pm 10.7$ vs. $36.9 \pm 5.9 ; p=0.04)$. In patients with normal renal function without metabolic syndrome (C-nMS), the intensity of anxiety trait (X2) decreased not significantly ( $40.1 \pm 9.7$ vs. $37.7 \pm 7.8 ; p=0.08)$. The difference in the intensity of trait anxiety (X2) between HD-nMS and C-nMS was still non-significant (Table 5). More data are provided in Supplementary Tables S2 and S4.

Table 5. Effect of rehabilitation program on the studied parameters in the study (HD) and control group (C) without metabolic syndrome (nMS).

\begin{tabular}{|c|c|c|c|c|c|c|}
\hline & \multicolumn{2}{|c|}{$\begin{array}{l}\text { Study Group } \\
\text { (HD-nMS) }\end{array}$} & \multicolumn{2}{|c|}{$\begin{array}{l}\text { Control Group } \\
\text { (C-nMS) }\end{array}$} & \multicolumn{2}{|c|}{$\begin{array}{c}p \text {-Value } \\
\text { HD-nMS vs. C-nMS }\end{array}$} \\
\hline & Before & After & Before & After & Before & After \\
\hline \multirow{2}{*}{$\mathrm{X} 1(\bar{x} \pm \mathrm{SD})$} & $34.5 \pm 8.2$ & $29.1 \pm 5.1$ & $31.2 \pm 7.3$ & $30.1 \pm 7.7$ & 026 & 095 \\
\hline & \multicolumn{2}{|c|}{$p=0.09$} & \multicolumn{2}{|c|}{$p=0.54$} & 0.26 & 0.95 \\
\hline \multirow{2}{*}{$\mathrm{X} 2(\bar{x} \pm \mathrm{SD})$} & $41.9 \pm 10.7$ & $36.9 \pm 5.9$ & $40.1 \pm 9.7$ & $37.7 \pm 7.8$ & 084 & 0.56 \\
\hline & \multicolumn{2}{|c|}{$p=0.04$} & \multicolumn{2}{|c|}{$p=0.08$} & 0.84 & \\
\hline
\end{tabular}

Note: Results are the mean \pm SD; significant at $p$-value $<0.05$. Abbreviations: X1, state anxiety; X2, trait anxiety; HD-nMS, hemodialysis patients without metabolic syndrome; C-nMS, patients with normal renal function without metabolic syndrome. 


\section{Discussion}

The main goal of our study was to determine whether the changes in anxiety intensity in HD patients and those with normal kidney function following the four-week rehabilitation program differed depending on the presence of MS. None of the previous studies on the relationship between physical activity and anxiety in HD patients considered the possible differences associated with MS.

An increasing number of authors emphasize the relationship between psychological conditions, especially anxiety and depression, with the development of somatic diseases and the influence of somatic disorders, especially chronic ones, on the occurrence of mental illnesses. Vasilopoulou et al. showed that a significant percentage of HD patients experienced a high level of anxiety or suffered from depression $(47.8 \% ; 38.2 \%$, respectively) [54]. Epidemiological studies have shown that the life expectancy of patients with severe mental disorders is reduced by 7 to 24 years. Anxiety is one of the strongest predictors of depression. Many studies have confirmed the relationship between anxiety and mortality [55]. Therefore, it is beyond dispute that the search for methods of reducing distress in HD patients is one of the essential directions of care for this group of patients.

There have been many attempts to determine the relationship between anxiety and metabolic syndrome (MS) in subjects with normal kidney function [56]. Most of the authors suggested the need for further prospective studies to determine a two-way relationship between these clinical conditions [57]. Intervention studies in subjects without renal failure distinctly indicate that regular exercise can reduce anxiety symptoms and possibly depression [46-48,58].

The present study shows that the level of anxiety-state (X1) was higher in HD patients with metabolic syndrome (HD-MS) than in individuals with normal renal function (C-MS). Interestingly, in the absence of metabolic syndrome in HD patients, state anxiety (X1) did not differ significantly from state anxiety $(\mathrm{X} 1)$ in subjects with normal kidney function. That indicates a significant influence of MS in the development of state anxiety in the studied patients.

The results of studies conducted so far, which did not consider the presence of the metabolic syndrome, indicate similarly to our observations that the intensity of anxiety in patients with uremia is significantly higher than in patients with normal renal function [59]. However, this study took into account the division into state anxiety and trait anxiety and has shown that the intensity of trait anxiety (X2) did not differ significantly in the entire group of HD patients compared to those with normal renal function.

The essential element of the presented work was an intervention consisting of a fourweek, well-controlled physical effort adjusted to the patient's abilities. The psychological effects of exercise in overweight or obese people are known [60]. Exercise alleviates symptoms of depression and anxiety and improves the quality of life [61-63].

The state anxiety (X1) decreased after four weeks of exercise, both in HD-MS patients and those with normal renal function (C-MS), but this change was significant only in patients with MS. The different response to physical exercise in HD patients in the sense of state anxiety is interesting (X1). Patients with metabolic syndrome benefited, in this case, more than patients without metabolic syndrome. State anxiety is a momentary and transient emotional response. The difference may be related to the rapid improvement in overall physical performance and weight loss with daily exercise, which is more noticeable in patients with MS. It may also be possible to improve your body image and increase your self-esteem after four weeks of regular exercise.

Trait anxiety which is understood as an individual and relatively permanent disposition to react with anxiety and perceive a given situation as threatening was also assessed. Although the differences between the initial and final severity of trait anxiety were significant in all HD patients and with normal renal function, differences in the severity of trait anxiety were observed depending on the presence of MS. In the absence of the metabolic syndrome, the change in the intensity of trait anxiety was significant in hemodialysis patients (HD-nMS) and subjects with normal renal function trait anxiety decreased only in 
patients with diagnosed metabolic syndrome (C-MS). Based on the above observations, it can be cautiously assumed that in terms of the impact of rehabilitation on the perception of trait anxiety (X2), there are differences due to the presence or absence of metabolic syndrome between HD patients and those with normal kidney function. This could suggest that non-MS HD patients benefit more in terms of reducing the severity of trait anxiety (X2) compared to patients with metabolic syndrome. This may be clinically relevant because, as shown in other studies [64], trait anxiety (X2) is most strongly associated with depressive symptoms.

In subjects with normal renal function, the subgroup with features of the metabolic syndrome showed more prominent benefits after the rehabilitation program in terms of state anxiety (X1) and trait anxiety (X2). The impact of exercise on anxiety in HD patients has been the subject of few studies so far. Our observations on the influence of physical activity on the feeling of distress confirmed the earlier reports of other authors, who suggested that regular physical exercise improves mood primarily when it is lowered and reduces the intensity of anxiety [46-48].

The general mechanisms of the influence of physical activity on reducing depression and anxiety disorders in various populations have been the subject of many studies. The presented hypotheses are primarily based on two theories: psychological and biological. The explanation of beneficial changes after exercise refers to two psychological trends: selfefficacy and the so-called the theory of distractors [65-67]. The change in self-esteem helps to regain conviction about the possibility of controlling one's behavior and achieve personal goals [68]. The aim of distractors is to take your attention away from fears, worries, and other negative psychological stimuli. Among the biological hypotheses, the $\beta$-endorphin theory stands out. After exercise, an increase in the serum concentration of $\beta$-endorphin metabolites released by the pituitary gland was found $[69,70]$. Another attempt to explain the improvement of mood after exercise may be the thermogenic theory. Body temperature increases during physical exertion, which may reduce muscle and mental tension [71]. Studies by other authors have also shown the effect of exercise on the hypothalamicpituitary-adrenal (HPA) system. The impact depends on the training load. Intense exercise causes a significant stimulation of the HPA axis. Long-term exercise with lighter loads reduces the reactivity of HPA [72]. The effect of physical exercise on improving mood may also be the result of the direct effect of exercise on increasing serotonin levels [73]. Moreover, physical exercise reduces fatigue and pain in the musculoskeletal system, increases muscle strength, and at the same time improves physical and mental performance $[30,73,74]$ and has a beneficial effect on the cardiovascular system [29].

Regular physical activity leads to a decreased concentration of C-reactive protein and the concentration of pro-inflammatory cytokines such as IL- 6 and TNF- $\alpha$. However, data on a significant reduction of pro-inflammatory cytokines after physical activity programs in HD patients are inconclusive $[49,75]$. Reducing the concentration of pro-inflammatory cytokines may improve the functioning of the neurotransmitter system responsible for regulating mood-mainly serotonin, noradrenaline, and dopamine. That is consistent with the inflammatory theory of depression. However, it is not possible to state without any doubt that improved mood in subjects participating in the four-week rehabilitation program was the result of solely increased physical activity. The conditions during the stay in the rehabilitation department differed from those in everyday life. That could have contributed to improving the mental state. It is safe to assume that the number of stressors in everyday life has decreased. Increased social contacts could also have had a positive effect on the patient's mood. The patients' attitude towards improving their well-being was also essential. Psychology refers to it as a self-fulfilling prophecy. Many positive changes in tension and anxiety were also observed by other researchers after various forms of physical activity [26-28]. On the other hand, the rehabilitation program involved a stay in a rehabilitation ward, which could exacerbate the symptoms of anxiety and depression.

Other authors observed a beneficial effect of physical activity in reducing anxiety in patients with various chronic clinical conditions [76,77]. However, there is still little 
data confirming these observations in HD patients [78]. Dziubek et al. [79] assessed the impact of a six-month regular exercise program on symptoms of depression and anxiety during the HD procedure. State anxiety lowered after endurance exercise, and there was a reverse response after resistance exercise. Hemodialysis is one of the sources of distress. It may have been more difficult for the authors of this study to achieve favorable changes in the perception of resistance exercise during HD. Unlike in our research, the intensity of trait anxiety has not changed significantly. Another difference between our research and that of other authors was that our patients performed the exercises outside HD procedures as part of a stationary rehabilitation program. While some studies indicate a relationship between metabolic syndrome and depression $[7,8]$, there is much less data on the relationship between MS and anxiety disorders and anxiety $[9,10,77]$. However, many researchers unanimously emphasize that distress should be recognized and treated as soon as possible [54].

Based on the conducted research, it is difficult to clearly explain the differentiation of the psychological effects of the four-week rehabilitation program based on the presence or absence of metabolic syndrome. The duration of the positive change in anxiety reduction was also not established. That could guide future research. It is likely that there are many direct and indirect mechanisms explaining the effect of MS on differences in response to exercise.

The presented study had several limitations. It was conducted in a relatively small group of subjects, and the observation period was relatively short. Moreover, the study included patients from one center, which makes generalizations difficult. However, singlecenter studies have allowed us to eliminate confounding factors associated with different standards and procedures.

The strength of our study was the way the exercises were managed. They occurred daily according to an individually selected scheme, during a four-week stay in stationary conditions, which guaranteed constant supervision of a multidisciplinary team and obtaining a very high level of compliance in the range of $90 \%$ to $100 \%$. Thus far, this study design has not been employed in HD patients in any available reports. Another strong point of the study was having full access to information on the treatment of HD patients and maintaining the same methodology of studies conducted directly by the same researchers. The added value of the study was also the preparation and motivation of patients for regular physical activity after the end of the rehabilitation program.

These observations are of practical importance. They can play a role in creating specific recommendations for exercise in HD patients with MS. They also draw attention to the need for a more accurate diagnosis of patients with anxiety disorders and a more precise selection of measures to reduce the intensity of anxiety, taking into account the presence of metabolic syndrome. Clinical evaluation of anxiety disorders should be performed repeatedly: at the start of HD, as part of the annual mental health assessment when coexisting depression is suspected after critical life stressors occur, whenever there is a marked change in patients' health, when treatment is not adhered to, or when there is unexplained and bothersome behavior by the patient in the dialysis station.

The actions reducing the perception of anxiety are all the more important as, according to other authors, depressive disorders and the accompanying distress that arises from complications of chronic kidney disease increase mortality, worsen the quality of life of patients, and contribute to non-adherence to treatment recommendations [80,81]. Ongoing anxiety assessment can help to stratify risk and identify patients at risk of death and cardiovascular morbidity [25]. The role of metabolic syndrome in response to exercise in HD patients should guide future research.

To summarize: after a four-week rehabilitation program, the severity of anxiety decreased in both HD patients and individuals with normal kidney function. In HD patients, the intensity of state anxiety was higher than in those with normal kidney function. The level of trait anxiety in HD patients did not differ from that in individuals with normal renal function. Unlike in the group with normal kidney function, the presence of MS was 
associated with higher levels of state anxiety in HD patients as compared to controls with normal renal function. The response to the four-week supervised rehabilitation program was different in HD patients as compared to controls with normal renal function. Beneficial reduction of trait anxiety (X2) was observed in HD-nMS patients. That was not the case for controls with normal renal function, among whom a considerable reduction of trait anxiety severity (X2) was associated with the presence of MS. It is important to note that the state anxiety (X1) significantly decreased both in HD patients and in individuals with normal kidney function only in the presence of MS.

This study enhances the insufficient literature on the effect of physical activity on reducing level of anxiety in HD patients, including metabolic syndrome. The research has scientific implications, especially in the context of reverse epidemiology in patients with end-stage renal disease. This study indicates the need to consider the presence or absence of MS in predicting the effect of physical activity on anxiety reduction in HD patients. The way the dialysis staff and HD patients understand the importance of physical activity in reducing the level of anxiety may fortify the effort to promote regular nephrological rehabilitation programs and physical activity during dialysis and between dialysis periods.

Our study did not analyze how long the reduced anxiety effect lasted after the rehabilitation program. Future research should identify the duration of the beneficial changes and other potential factors that influence the relationship between the effectiveness of physical activity in reducing anxiety.

\section{Conclusions}

1. Four-week physical activity planned and adapted to the patient's abilities reduces the intensity of anxiety in HD patients and controls with normal renal function.

2. HD patients with MS benefit more with regard to reducing perceived state anxiety and HD patients without MS in terms of reducing trait anxiety.

3. In patients with normal kidney function without metabolic syndrome, the rehabilitation program did not significantly reduce state anxiety and trait anxiety, unlike patients with normal kidney function with metabolic syndrome in whom anxiety state and trait anxiety decreased.

Supplementary Materials: The following are available online at https: / www.mdpi.com/article / 10.3390/ijerph182211952/s1. Table S1: Comparison of items of the STAI questionnaire before and after the rehabilitation program in the study and control group. Table S2: Comparison of items of the STAI questionnaire before and after the rehabilitation program in the study and control group with metabolic syndrome and without metabolic syndrome. Table S3: Comparison of mean values of items of the STAI questionnaire before and after the rehabilitation program in the study and control group. Table S4: Comparison of mean values of items of the STAI questionnaire before and after the rehabilitation program in the study and control group with metabolic syndrome and without metabolic syndrome.

Author Contributions: Conceptualization, B.H., J.D. (Jan Duława), and J.D. (Jacek Durmała); methodology, B.H. and J.D. (Jan Duława); formal analysis, B.H.; investigation, B.H.; data curation, B.H.; writing — original draft preparation, B.H. and J.D. (Jan Duława); writing—review and editing, B.H., J.D. (Jan Duława), and J.D. (Jacek Durmała); supervision, B.H., J.D. (Jan Duława), and J.D. (Jacek Durmała); project administration, B.H. and J.D. (Jan Duława); funding acquisition, B.H. All authors have read and agreed to the published version of the manuscript.

Funding: This project was supported by a Medical University of Silesia in Katowice grant to statutory work (Contract KNW-1-035/N/8/Z).

Institutional Review Board Statement: The study was conducted according to the guidelines of the Declaration of Helsinki and approved by the Bioethical Committee of the Medical University of Silesia in Katowice (Resolution No. KNW/0022/KB1/44/II/06/14/17).

Informed Consent Statement: Informed consent was obtained from all subjects involved in the study. 
Data Availability Statement: The results of scientific studies are anonymized and will be stored as such in an electronic form in a structured Statistica format on the premises of the facility conducting the study. The data will be stored for a period of 15 years. If requested, it can be made available in an anonymized form to the publisher within the scope of the presented work. Personal data related to this research are kept on the premises of the medical facility where the studies have been conducted. The data are subject to provisions on data protection in accordance with the law (Patients' Rights and Patients' Rights Ombudsman Article 26 Section 4).

Acknowledgments: We wish to thank the doctors, physiotherapists, and nurses for their courteousness in carrying out the study and the psychologists for their help with interpreting the results.

Conflicts of Interest: The authors declare no conflict of interest. The funders had no role in the design of the study; in the collection, analyses, or interpretation of data; in the writing of the manuscript; or in the decision to publish the results. The results presented in this paper have not been published previously in whole or in part.

\section{References}

1. Syukri, M.; Virnardo, R.; Salwani, D.; Abdullah, A.; Sofyan, H.; Marthoenis, M. The prevalence and associated factors of metabolic syndrome among patients with end-stage renal failure undergoing hemodialysis in Indonesia. Diabetes Metab. Syndr. Clin. Res. Rev. 2020, 14, 2069-2072. [CrossRef] [PubMed]

2. Vogt, B.P.; Souza, P.L.; Minicucci, M.F.; Martin, L.C.; Barretti, P.; Caramori, J.T. Metabolic Syndrome Criteria as Predictors of Insulin Resistance, Inflammation and Mortality in Chronic Hemodialysis Patients. Metab. Syndr. Relat. Disord. 2014, 12, 443-449. [CrossRef] [PubMed]

3. Alswat, K.A.; Althobaiti, A.; Alsaadi, K.; Alkhaldi, A.S.; Alharthi, M.M.; Abuharba, W.A.; Alzaidi, A.A. Prevalence of Metabolic Syndrome among the End-Stage Renal Disease Patients on Hemodialysis. J. Clin. Med. Res. 2017, 9, 687. [CrossRef] [PubMed]

4. Kahl, K.G.; Schweiger, U.; Correll, C.; Müller, C.; Busch, M.-L.; Bauer, M.; Schwarz, P. Depression, Anxiety Disorders, and Metabolic Syndrome in a Population at Risk for Type 2 Diabetes Mellitus. Brain Behav. 2015, 5, e00306. [CrossRef] [PubMed]

5. Haufe, S.; Kahl, K.G.; Kerling, A.; Protte, G.; Bayerle, P.; Stenner, H.T.; Rolff, S.; Sundermeier, T.; Eigendorf, J.; Kück, M.; et al. Employers With Metabolic Syndrome and Increased Depression/Anxiety Severity Profit Most From Structured Exercise Intervention for Work Ability and Quality of Life. Front. Psychiatry 2020, 11, 562. [CrossRef] [PubMed]

6. Takeuchi, T.; Nakao, M.; Nomura, K.; Inoue, M.; Tsurugano, S.; Shinozaki, Y.; Yano, E. Association of the Metabolic Syndrome with Depression and Anxiety in Japanese Men: A 1-Year Cohort Study. Diabetes Metab. Res. Rev. 2009, 25, 762-767. [CrossRef]

7. Butnoriene, J.; Bunevicius, A.; Norkus, A.; Bunevicius, R. Depression but Not Anxiety Is Associated with Metabolic Syndrome in Primary Care Based Community Sample. Psychoneuroendocrinology 2014, 40, 269-276. [CrossRef]

8. Skilton, M.R.; Moulin, P.; Terra, J.L.; Bonnet, F. Associations between anxiety, depression, and the metabolic syndrome. Biol. Psychiatry 2007, 62, 1251-1257. [CrossRef]

9. Pan, A.; Keum, N.; Okereke, O.I.; Sun, Q.; Kivimaki, M.; Rubin, R.R.; Hu, F.B. Bidirectional Association between Depression and Metabolic Syndrome: A Systematic Review and Meta-Analysis of Epidemiological Studies. Diabetes Care 2012, 35, 1171-1180. [CrossRef] [PubMed]

10. Roohafza, H.; Sadeghi, M.; Talaei, M.; Pourmoghaddas, Z.; Sarrafzadegan, N. Psychological Status and Quality of Life in Relation to the Metabolic Syndrome: Isfahan Cohort Study. Int. J. Endocrinol. 2012, 2012, 380902. [CrossRef]

11. Kessler, R.C.; Aguilar-Gaxiola, S.; Alonso, J.; Chatterji, S.; Lee, S.; Ormel, J.; Üstün, T.B.; Wang, P.S. The Global Burden of Mental Disorders: An Update from the WHO World Mental Health (WMH) Surveys. Epidemiol. Psychiatr. Sci. 2009, 18, 23-33. [CrossRef]

12. Kroenke, K.; Spitzer, R.L.; Williams, J.B.; Monahan, P.O.; Löwe, B. Anxiety Disorders in Primary Care: Prevalence, Impairment, Comorbidity, and Detection. Ann. Intern. Med. 2007, 146, 317-325. [CrossRef]

13. Murtagh, F.E.M.; Addington-Hall, J.; Higginson, I.J. The Prevalence of Symptoms in End-Stage Renal Disease: A Systematic Review. Adv. Chronic Kidney Dis. 2007, 14, 82-99. [CrossRef] [PubMed]

14. De Brito, D.C.S.; Machado, E.L.; Reis, I.A.; de Freitas do Carmo, L.P.; Cherchiglia, M.L. Depression and Anxiety among Patients Undergoing Dialysis and Kidney Transplantation: A Cross-Sectional Study. Sao Paulo Med. J. 2019, 137, 137-147. [CrossRef] [PubMed]

15. Kutner, N.G.; Fair, P.L.; Kutner, M.H. Assessing Depression and Anxiety in Chronic Dialysis Patients. J. Psychosom. Res. 1985, 29, 23-31. [CrossRef]

16. Nassim, M.; Park, H.; Dikaios, E.; Potes, A.; Elbaz, S.; Mc Veigh, C.; Lipman, M.; Novak, M.; Trinh, E.; Alam, A.; et al. Brief Mindfulness Intervention vs. Health Enhancement Program for Patients Undergoing Dialysis: A Randomized Controlled Trial. Healthcare 2021, 9, 659. [CrossRef] [PubMed]

17. Al-Shammari, N.; Al-Modahka, A.; Al-Ansari, E.; Al-Kandari, M.; Ibrahim, K.A.; Al-Sanea, J.; Al-Sabah, R.; Albatineh, A.N. Prevalence of Depression, Anxiety, and Their Associations among End-Stage Renal Disease Patients on Maintenance Hemodialysis: A Multi-Center Population-Based Study. Psychol. Health Med. 2020, 26, 1134-1142. [CrossRef] [PubMed]

18. Stein, M.B.; Sareen, J. Generalized Anxiety Disorder. N. Engl. J. Med. 2015, 373, 2059-2068. [CrossRef] 
19. Kurella, M.; Kimmel, P.L.; Young, B.S.; Chertow, G.M. Suicide in the United States End-Stage Renal Disease Program. J. Am. Soc. Nephrol. 2005, 16, 774-781. [CrossRef] [PubMed]

20. Lavie, C.J.; Menezes, A.R.; De Schutter, A.; Milani, R.V.; Blumenthal, J.A. Impact of Cardiac Rehabilitation and Exercise Training on Psychological Risk Factors and Subsequent Prognosis in Patients with Cardiovascular Disease. Can. J. Cardiol. 2016, 32, 365-373. [CrossRef] [PubMed]

21. Mikhaylov, A.Y.; Yumashev, A.V.; Kolpak, E. Quality of Life, Anxiety and Depressive Disorders in Patients with Extrasystolic Arrhythmia. Arch. Med. Sci. 2020, 18, 1-8. [CrossRef]

22. Karlsen, H.R.; Saksvik-Lehouillier, I.; Stone, K.L.; Schernhammer, E.; Yaffe, K.; Langvik, E. Anxiety as a Risk Factor for Cardiovascular Disease Independent of Depression: A Prospective Examination of Community-Dwelling Men (the MrOS Study). Psychol. Health 2020, 36, 148-163. [CrossRef] [PubMed]

23. Tully, P.J.; Baker, R.A.; Knight, J.L. Anxiety and Depression as Risk Factors for Mortality after Coronary Artery Bypass Surgery. J. Psychosom. Res. 2008, 64, 285-290. [CrossRef]

24. Székely, A.; Balog, P.; Benkö, E.; Breuer, T.; Székely, J.; Kertai, M.D.; Horkay, F.; Kopp, M.S.; Thayer, J.F. Anxiety Predicts Mortality and Morbidity after Coronary Artery and Valve Surgery-a 4-Year Follow-up Study. Psychosom. Med. 2007, 69, 625-631. [CrossRef] [PubMed]

25. Frasure-Smith, N.; Lespérance, F. Depression and Anxiety as Predictors of 2-Year Cardiac Events in Patients with Stable Coronary Artery Disease. Arch. Gen. Psychiatry 2008, 65, 62-71. [CrossRef] [PubMed]

26. Da Silva, M.A.; Singh-Manoux, A.; Brunner, E.J.; Kaffashian, S.; Shipley, M.J.; Kivimäki, M.; Nabi, H. Bidirectional Association Between Physical Activity and Symptoms of Anxiety and Depression: The Whitehall II Study. Eur. J. Epidemiol. 2012, 27, 537-546. [CrossRef] [PubMed]

27. Awick, E.A.; Ehlers, D.K.; Aguiñaga, S.; Daugherty, A.M.; Kramer, A.F.; McAuley, E. Effects of a Randomized Exercise Trial on Physical Activity, Psychological Distress and Quality of Life in Older Adults. Gen. Hosp. Psychiatry 2017, 49, 44-50. [CrossRef] [PubMed]

28. McDowell, C.P.; Dishman, R.K.; Gordon, B.R.; Herring, M.P. Physical Activity and Anxiety: A Systematic Review and MetaAnalysis of Prospective Cohort Studies. Am. J. Prev. Med. 2019, 57, 545-556. [CrossRef]

29. Baumeister, S.E.; Leitzmann, M.F.; Bahls, M.; Dörr, M.; Schmid, D.; Schomerus, G.; Appel, K.; Markus, M.R.P.; Völzke, H.; Gläser, S.; et al. Associations of Leisure-Time and Occupational Physical Activity and Cardiorespiratory Fitness with Incident and Recurrent Major Depressive Disorder, Depressive Symptoms, and Incident Anxiety in a General Population. J. Clin. Psychiatry 2017, 78, e41-e47. [CrossRef] [PubMed]

30. Kandola, A.; Vancampfort, D.; Herring, M.; Rebar, A.; Hallgren, M.; Firth, J.; Stubbs, B. Moving to Beat Anxiety: Epidemiology and Therapeutic Issues with Physical Activity for Anxiety. Curr. Psychiatry Rep. 2018, 20, 63. [CrossRef] [PubMed]

31. Stubbs, B.; Koyanagi, A.; Hallgren, M.; Firth, J.; Richards, J.; Schuch, F.; Rosenbaum, S.; Mugisha, J.; Veronese, N.; Lahti, J.; et al. Physical Activity and Anxiety: A Perspective from the World Health Survey. J. Affect. Disord. 2017, 208, 545-552. [CrossRef]

32. Carter, T.; Pascoe, M.; Bastounis, A.; Morres, I.D.; Callaghan, P.; Parker, A.G. The Effect of Physical Activity on Anxiety in Children and Young People: A Systematic Review and Meta-Analysis. J. Affect. Disord. 2021, 285, 10-21. [CrossRef]

33. Teychenne, M.; Costigan, S.A.; Parker, K. The Association between Sedentary Behaviour and Risk of Anxiety: A Systematic Review. BMC Public Health 2015, 15, 513. [CrossRef] [PubMed]

34. Amini, E.; Goudarzi, I.; Masoudi, R.; Ahmadi, A.; Momeni, A. Effect of Progressive Muscle Relaxation and Aerobic Exercise on Anxiety, Sleep Quality, and Fatigue in Patients with Chronic Renal Failure Undergoing Hemodialysis. Int. J. Pharmceut. Clin. Res. 2016, 8, 1634-1639.

35. Cho, J.H.; Lee, J.Y.; Lee, S.; Park, H.; Choi, S.W.; Kim, J.C. Effect of Intradialytic Exercise on Daily Physical Activity and Sleep Quality in Maintenance Hemodialysis Patients. Int. Urol. Nephrol. 2018, 50, 745-754. [CrossRef] [PubMed]

36. Kouidi, E.; Karagiannis, V.; Grekas, D. Depression, Heart Rate Variability, and Exercise Training in Dialysis Patients. Eur. J. Cardiovasc. Prev. Rehabil. 2010, 17, 160-167. [CrossRef]

37. van Vilsteren, M.C.; de Greef, M.H.; Huisman, R.M. The effects of a low-to-moderate intensity pre-conditioning exercise programme linked with exercise counselling for sedentary haemodialysis patients in The Netherlands: Results of a randomized clinical trial. Nephrol. Dial. Transplant. 2005, 20, 141-146. [CrossRef]

38. Giannaki, C.D.; Hadjigeorgiou, G.M.; Karatzaferi, C.; Maridaki, M.D.; Koutedakis, Y.; Founta, P.; Tsianas, N.; Stefanidis, J.; Sakkas, G.K. A Single-blind Randomized Controlled Trial to Evaluate the Effect of 6 Months of Progressive Aerobic Exercise Training in Patients with Uraemic Restless Legs Syndrome. Nephrol. Dial. Transplant. 2013, 28, 2834-2840. [CrossRef] [PubMed]

39. Bohm, C.; Schick-Makaroff, K.; MacRae, J.M.; Tan, M.; Thompson, S. The Role of Exercise in Improving Patient-reported Outcomes in Individuals on Dialysis: A Scoping Review. Semin. Dial. 2019, 32, 336-350. [CrossRef] [PubMed]

40. Aucella, F.; Valente, G.L.; Catizone, L. The Role of Physical Activity in the CKD Setting. Kidney Blood Press. Res. 2014, 39, 97-106. [CrossRef] [PubMed]

41. Kalantar-Zadeh, K.; Abbott, K.C.; Salahudeen, A.K.; Kilpatrick, R.D.; Horwich, T.B. Survival advantages of obesity in dialysis patients. Am. J. Clin. Nutr. 2005, 81, 543-554. [CrossRef]

42. Kalantar-Zadeh, K.; Kilpatrick, R.D.; Mcallister, C.J.; Greenland, S.; Kopple, J.D. Reverse Epidemiology of Hypertension and Cardiovascular Death in the Hemodialysis Population: The 58th Annual Fall Conference and Scientific Sessions. Hypertension 2005, 45, 811-817. [CrossRef] [PubMed] 
43. Cabezas-Rodriguez, I.; Carrero, J.J.; Zoccali, C.; Qureshi, A.R.; Ketteler, M.; Floege, J.; London, G.; Locatelli, F.; Gorriz, J.L.; Rutkowski, B.; et al. Influence of Body Mass Index on the Association of Weight Changes with Mortality in Hemodialysis Patients. Clin. J. Am. Soc. Nephrol. 2013, 8, 1725-1733. [CrossRef]

44. Moradi, H.; Streja, E.; Kashyap, M.L.; Vaziri, N.D.; Fonarow, G.C.; Kalantar-Zadeh, K. Elevated High-Density Lipoprotein Cholesterol and Cardiovascular Mortality in Maintenance Hemodialysis Patients. Nephrol. Dial. Transplant. 2014, 29, 1554-1562. [CrossRef] [PubMed]

45. Lu, J.L.; Kalantar-Zadeh, K.; Ma, J.Z.; Quarles, L.D.; Kovesdy, C.P. Association of Body Mass Index with Outcomes in Patients with CKD. J. Am. Soc. Nephrol. 2014, 25, 2088-2096. [CrossRef] [PubMed]

46. Schuch, F.B.; Vancampfort, D.; Firth, J.; Rosenbaum, S.; Ward, P.B.; Silva, E.S.; Hallgren, M.; Ponce De Leon, A.; Dunn, A.L.; Deslandes, A.C.; et al. Physical Activity and Incident Depression: A Meta-Analysis of Prospective Cohort Studies. Am. J. Psychiatry 2018, 175, 631-648. [CrossRef] [PubMed]

47. Schuch, F.B.; Stubbs, B.; Meyer, J.; Heissel, A.; Zech, P.; Vancampfort, D.; Rosenbaum, S.; Deenik, J.; Firth, J.; Ward, P.B.; et al. Physical activity protects from incident anxiety: A meta-analysis of prospective cohort studies. Depress. Anxiety 2019, 36, 846-858. [CrossRef]

48. Rebar, A.L.; Stanton, R.; Geard, D.; Short, C.; Duncan, M.J.; Vandelanotte, C. A Meta-Meta-Analysis of the Effect of Physical Activity on Depression and Anxiety in Non-Clinical Adult Populations. Health Psychol. Rev. 2015, 9, 366-378. [CrossRef] [PubMed]

49. Hornik, B.; Duława, J.; Szewieczek, J.; Durmała, J. Physical Activity Increases the Resistin Concentration in Hemodialyzed Patients without Metabolic Syndrome. Diabetes Metab. Syndr. Obes. 2018, 12, 43-57. [CrossRef] [PubMed]

50. Alberti, K.G.; Eckel, R.H.; Grundy, S.M.; Zimmet, P.Z.; Cleeman, J.I.; Donato, K.A.; Fruchart, J.-C.; James, W.P.T.; Loria, C.M.; Smith, S.C., Jr. Harmonizing the metabolic syndrome: A joint interim statement of the international diabetes federation task force on epidemiology and prevention; national heart, lung, and blood institute; American heart association; world heart federation; international atherosclerosis society; and international association for the study of obesity. Circulation 2009, 120, 1640-1645. [CrossRef] [PubMed]

51. Spielberger, C.D. Anxiety: State -trait -process. In Stress and Anxiety; Spielberger, C.D., Sarason, I.G., Eds.; Hemisphere/Wiley: Washington, DC, USA, 1975; Volume 1, pp. 115-143.

52. Wrześniewski, K.; Sosnowski, T.; Jaworowska, A.; Fecenec, D. Inwentarz Stanu i Cechy Lęku—Polska Adaptacja STAI, 4th ed.; Pra-cownia Testów Psychologicznych Polskiego Towarzystwa Psychologicznego sp. z o.o. (Psychological Tests Laboratory, Polish Psychological Association): Warsaw, Poland, 2011.

53. Borg, G.A. Psychophysical Bases of Perceived Exertion. Med. Sci. Sports Exerc. 1982, 14, 377-381. [CrossRef]

54. Vasilopoulou, C.; Bourtsi, E.; Giaple, S.; Koutelekos, I.; Theofilou, P.; Polikandrioti, M. The Impact of Anxiety and Depression on the Quality of Life of Hemodialysis Patients. Glob. J. Health Sci. 2015, 8, 45-55. [CrossRef] [PubMed]

55. Chesney, E.; Goodwin, G.M.; Fazel, S. Risks of All-cause and Suicide Mortality in Mental Disorders: A Meta-review. World Psychiatry 2014, 13, 153-160. [CrossRef]

56. Vuong, E.; Nothling, J.; Lombard, C.; Jewkes, R.; Peer, N.; Abrahams, N.; Seedat, S. Peripheral Adiponectin Levels in Anxiety, Mood, Trauma- and Stressor-Related Disorders: A Systematic Review and Meta-Analysis. J. Affect. Disord. 2020, 260, 372-409. [CrossRef] [PubMed]

57. Tang, F.; Wang, G.; Lian, Y. Association between Anxiety and Metabolic Syndrome: A Systematic Review and Meta-Analysis of Epidemiological Studies. Psychoneuroendocrinology 2017, 77, 112-121. [CrossRef] [PubMed]

58. Stubbs, B.; Vancampfort, D.; Hallgren, M.; Firth, J.; Veronese, N.; Solmi, M.; Brand, S.; Cordes, J.; Malchow, B.; Gerber, M.; et al. EPA guidance on physical activity as a treatment for severe mental illness: A meta-review of the evidence and Position Statement from the European Psychiatric Association (EPA), supported by the International Organization of Physical Therapists in Mental Health (IOPTMH). Eur. Psychiatry 2018, 54, 124-144. [CrossRef] [PubMed]

59. van Sandwijk, M.S.; Al Arashi, D.; van de Hare, F.M.; van der Torren, J.M.R.; Kersten, M.J.; Bijlsma, J.A.; Ten Berge, I.J.M.; Bemelman, F.J. Fatigue, Anxiety, Depression and Quality of Life in Kidney Transplant Recipients, Haemodialysis Patients, Patients with a Haematological Malignancy and Healthy Controls. Nephrol. Dial. Transplant. 2019, 34, 833-838. [CrossRef] [PubMed]

60. Gill, A.; Kok, G.; Peters, G.J.Y.; Frissen, T.; Schols, A.M.; Plasqui, G. The Psychological Effects of Strength Exercises in People Who Are Overweight or Obese: A Sys.stematic Review. Sports Med. 2017, 47, 2069-2081. [CrossRef]

61. Hargrove, N.; El Tobgy, N.; Zhou, O.; Pinder, M.; Plant, B.; Askin, N.; Bieber, L.; Collister, D.; Whitlock, R.; Tangri, N.; et al. Effect of Aerobic Exercise on Dialysis-Related Symptoms in Individuals Undergoing Maintenance Hemodialysis. Clin. J. Am. Soc. Nephrol. 2021, 16, 560-574. [CrossRef] [PubMed]

62. Ghroubi, S.; Kossemtini, W.; Mahersi, S.; Elleuch, W.; Chaabene, M.; Elleuch, M.H. Contribution of Isokinetic Muscle Strengthening in the Rehabilitation of Obese Subjects. Ann. Phys. Rehabil. Med. 2016, 59, 87-93. [CrossRef] [PubMed]

63. Choi, J.I.; Cho, Y.H.; Kim, Y.J.; Lee, S.Y.; Lee, J.G.; Yi, Y.H.; Tak, Y.J.; Hwang, H.R.; Lee, S.H.; Park, E.J.; et al. The Relationship of Sitting Time and Physical Activity on the Quality of Life in Elderly People. Int. J. Environ. Res. Public Health 2021, $18,1459$. [CrossRef] [PubMed]

64. Dziubek, W.; Pawlaczyk, W.; Rogowski, L.; Stefanska, M.; Golebiowski, T.; Mazanowska, O.; Krajewska, M.; Kusztal, M.; Kowalska, J. Assessment of Depression and Anxiety in Patients with Chronic Kidney Disease and after Kidney TransplantationA Comparative Analysis. Int. J. Environ. Res. Public Health 2021, 18, 10517. [CrossRef] 
65. Bandura, A.; Freeman, W.H.; Lightsey, R. Self-efficacy: The exercise of control. J. Cogn. Psychother. 1999, 13, 158-166. [CrossRef]

66. Craft, L.L. Exercise and clinical depression: Examining two psychological mechanisms. Psychol. Sport Exerc. 2005, 6, 151-171. [CrossRef]

67. Kandola, A.; Ashdown-Franks, G.; Hendrikse, J.; Sabiston, C.M.; Stubbs, B. Physical Activity and Depression: Towards Understanding the Antidepressant Mechanisms of Physical Activity. Neurosci. Biobehav. Rev. 2019, 107, 525-539. [CrossRef] [PubMed]

68. Gruszkowska, M. Effects of Exercise on Anxiety, Depression and Mood. Psychiatr. Pol. 2004, 38, 611-620.

69. Goldfarb, A.H.; Jamurtas, A.Z. $\beta$-Endorphin response to exercise. Sports Med. 1997, 24, 8-16. [CrossRef]

70. Seime, R.J.; Vickers, K.S. The Challenges of Treating Depression with Exercise: From Evidence to Practice. Clin. Psychol. Sci. Pract. 2006, 13, 194-197. [CrossRef]

71. Hanusch, K.-U.; Janssen, C.H.; Billheimer, D.; Jenkins, I.; Spurgeon, E.; Lowry, C.A.; Raison, C.L. Whole-body hyperthermia for the treatment of major depression: Associations with thermoregulatory cooling. Am. J. Psychiatry 2013, 170, 802-804. [CrossRef] [PubMed]

72. Arent, S.M.; Landers, D.M.; Matt, K.S.; Etnier, J.L. Dose-response and mechanistic issues in the resistance training and affect relationship. J. Sport Exerc. Psychol. 2005, 27, 92-110. [CrossRef]

73. Zimmer, P.; Stritt, C.; Bloch, W.; Schmidt, F.P.; Hübner, S.T.; Binnebößel, S.; Schenk, A.; Oberste, M. The effects of different aerobic exercise intensities on serum serotonin concentrations and their association with Stroop task performance: A randomized controlled trial. Eur. J. Appl. Physiol. 2016, 116, 2025-2034. [CrossRef]

74. Haufe, S.; Kerling, A.; Protte, G.; Bayerle, P.; Stenner, H.T.; Rolff, S.; Sundermeier, T.; Kück, M.; Ensslen, R.; Nachbar, L.; et al. Telemonitoring-Supported Exercise Training, Metabolic Syndrome Severity, and Work Ability in Company Employees: A Randomised Controlled Trial. Lancet Public Health 2019, 4, e243-e352. [CrossRef]

75. Gleeson, M.; Bishop, N.; Stensel, D. The Anti-Inflammatory Effects of Exercise: Mechanisms and Implications for the Prevention and Treatment of Disease. Nat. Rev. Immunol. 2011, 11, 607-615. [CrossRef] [PubMed]

76. Chauvet-Gelinier, J.-C.; Bonin, B. Stress, Anxiety and Depression in Heart Disease Patients: A Major Challenge for Cardiac Rehabilitation. Ann. Phys. Rehabil. Med. 2017, 60, 6-12. [CrossRef] [PubMed]

77. Mattei, G.; Padula, M.S.; Rioli, G.; Arginelli, L.; Bursi, R.; Bursi, S.; Epifani, A.M.; Pingani, L.; Rigatelli, M.; Rosato, F.M.; et al. Metabolic Syndrome, Anxiety and Depression in a Sample of Italian Primary Care Patients. J. Nerv. Ment. Dis. 2018, 206, 316-324. [CrossRef] [PubMed]

78. Zhang, M.; Kim, J.C.; Li, Y.; Shapiro, B.B.; Porszasz, J.; Bross, R.; Feroze, U.; Upreti, R.; Martin, D.; Kalantar-Zadeh, K.; et al. Relation between Anxiety, Depression, and Physical Activity and Performance in Maintenance Hemodialysis Patients. J. Ren. Nutr. 2014, 24, 252-260. [CrossRef]

79. Dziubek, W.; Kowalska, J.; Kusztal, M.; Rogowski, Ł.; Gołębiowski, T.; Nikifur, M.; Szczepańska-Gieracha, J.; Zembroń-Łacny, A.; Klinger, M.; Woźniewski, M. The Level of Anxiety and Depression in Dialysis Patients Undertaking Regular Physical Exercise Training-A Preliminary Study. Kidney Blood Press. Res. 2016, 41, 86-98. [CrossRef] [PubMed]

80. Hornik, B.; Duława, J. Frailty, Quality of Life, Anxiety, and Other Factors Affecting Adherence to Physical Activity Recommendations by Hemodialysis Patients. Int. J. Environ. Res. Public Health 2019, 16, 1827. [CrossRef] [PubMed]

81. Jahromi, M.K.; Javadpour, S.; Taheri, L.; Poorgholami, F. Effect of Nurse-Led Telephone Follow Ups (Tele-Nursing) on Depression, Anxiety and Stress in Hemodialysis Patients. Glob. J. Health Sci. 2016, 8, 168. [CrossRef] [PubMed] 